PNL-SA-24828

\title{
ACCURACY ISSUES IN MODELING SUPERPLASTIC METAL FORMING
}

\author{
K. I. Johnson \\ M. A. Kahleel \\ C. A. Lavender \\ M. T. Smith
}

February 1995

Presented at the

Annual Meeting of The Minerals, Materials, and Metals

Society

February 13-15, 1995

Las Vegas, Nevada

Prepared for

the U.S. Department of Energy

under Contract DE-AC06-76RLO 1830

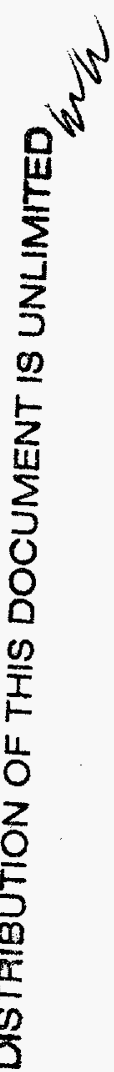

Pacific Northwest Laboratory

Richland, Washington 99352

\section{DISCLAIMER}

This report was prepared as an account of work sponsored by an agency of the United States Government. Neither the United States Government nor any agency thereof, nor any of their employees, makes any warranty, express or implied, or assumes any legal liability or responsibility for the accuracy, completeness, or usefulness of any information, apparatus, product, or process disclosed, or represents that its use would not infringe privately owned rights. Reference herein to any specific commercial product, process, or service by trade name, trademark, manufacturer, or otherwise does not necessarily constitute or imply its endorsement, recommendation, or favoring by the United States Government or any agency thereof. The views and opinions of authors expressed herein do not necessarily state or reflect those of the United States Government or any agency thereof. 


\section{DISCLAIMER}

Portions of this document may be illegible in electronic image products. Images are produced from the best available original document. 


\title{
ACCURACY ISSUES IN MODELING
}

\author{
SUPERPLASTIC METAL FORMING
}

\author{
K. I. Johnson, M.A. Khaleel, C. A. Lavender, and M. T. Smith \\ Pacific Northwest Laboratory \\ Richland, WA 99352
}

\begin{abstract}
The utility of finite element modeling in optimizing superplastic metal forming is dependent on accurate representation of the material constitutive behavior and the frictional response of the sheet against the die surface. This paper presents work conducted to estimate the level of precision that is necessary in constitutive relations for finite element analysis to accurately predict the deformation history of actual SPF components. Previous work identified errors in SPF testing methods that use short tensile specimens with gauge length-to-width ratios of 2:1 or less. The analysis of the present paper was performed to estimate the error in predicted stress that results from using the short specimens. Stress correction factors were developed and an improved constitutive relation was implemented in the MARC finite element code to simulate the forming of a long, rectangular tray. The coefficient of friction in a Coulomb friction model was adjusted to reproduce the amount of material draw-in observed in the forming experiments. Comparisons between the finite element predictions and the forming experiments are presented.
\end{abstract}

'PNL is operated for the U.S. Department of Energy by Battelle Memorial Institute under Contract DE-AC06-76RLO 1830. 


\section{Introduction}

Finite element models of the superplastic forming (SPF) process contain numerous approximations in progressing from basic materials test data to the final prediction of an optimized forming cycle. Approximations exist in 1) the material constitutive relations, 2) the friction model, 3) the finite element mesh discretization, and 4) the numerical solution method. Approximations in the material constitutive relation and the friction model directly influence the accuracy of the finite element model because these relations represent the forming behavior of a specific alloy as observed in laboratory tests. The constitutive relation influences the predicted forming rate for a given forming pressure history because it describes the flow stress as a function of strain rate, strain, and grain size. The friction model primarily influences the thickness profile of the formed part, although it also affects the overall forming rate to a lesser degree.

A previous study identified significant inaccuracies in the testing procedures that have typically been used to evaluate the constitutive behavior of SPF materials (1). These inaccuracies arise from the use of short-tension specimens; where end effects and material flow from the grips result in strain rates that begin considerably below the target value and increase to surpass the target strain rate later in the test. Therefore, constitutive models based on data from such tests are flawed because of this unexpected variation in strain rate during a test that was intended to be constant strain rate. The purpose of the current study is to investigate the level of error that exists in a constitutive model that was developed earlier from short-tension tests of aluminum alloy 5083. The constitutive relation described in (1) was modified to correct for the estimated error. Finite element models of a long, rectangular tray were then run with both the corrected and uncorrected constitutive models, and these results were compared against tray forming experiments.

\section{Results of Tension Test Modeling}

A finite element model was constructed to simulate the short-tension specimens (length-to-width ratio of $2: 1$ in the gauge length) used in collecting data for the constitutive relation. The model provided an estimate of the variation in the actual strain rate (at the center of the gauge length) from the target strain rate that was intended for the test. The tension test model used the constitutive relation developed in (1) for aluminum alloy 5083 at $525^{\circ} \mathrm{C}$. Least squares curve fitting was used to reduce the tension test data to the following constitutive form:

$$
\dot{\varepsilon}_{t o t}=\frac{A_{i i}\left(\sigma-\sigma_{0}\right)^{1 / M}}{d_{i}^{p}}+A_{i i i} \sigma^{n}
$$

where $\varepsilon$ is the equivalent strain rate, $M$ is the maximum strain rate sensitivity exponent, $p$ is the grain size exponent, $\mathrm{n}$ is the power law creep exponent, and $\sigma_{0}$ is the threshold flow stress. The constants $\mathrm{A}_{\mathrm{ii}}$ (the superplastic constant) and $\mathrm{A}_{\mathrm{iii}}$ (the creep constant) were determined from curve fitting. This equation gives the strain rate as a function of the current flow stress, $\sigma$, and total grain size, $d_{t}$. This form was suggested by Hamilton et al. (2) as a means of accounting for strain hardening due to static and deformation-enhanced grain growth. It should be stressed here that because the parameters for the current implementation of this constitutive relation were developed from several sources of test data, the model likely represents the general class of aluminum alloy 5083, but not necessarily the behavior of a specific source of this alloy. Indeed, PNL's forming experiments using Al-5083 produced by the Sky Aluminum Company show 
rather significant differences in the forming behavior of this alloy compared to the model predictions. In general, the tray forming experiments show slower forming than the models predict.

A displacement history of the form

$$
u(t)=L_{0}\left(e^{\dot{z}_{T} t}-1\right)
$$

was applied to the model, where $\mathrm{L}_{0}$ is the initial gauge length of the specimen. This displacement history would result in the target strain rate, $\dot{\varepsilon}_{\mathrm{T}}$, if the strain rate were constant throughout the gauge of the specimen and if no material flow occurred from the grips. However, Figure 1 shows the model predicts that the actual strain rate at the center of the specimen may initially be $35 \%$ lower than the target strain rate of $0.001 / \mathrm{second}$. This trend was experimentally confirmed by performing a series of interrupted tensile tests and measuring the change in area strain over a small time period to estimate the uniaxial strain rate.

\section{Estimating the Error in the Constitutive Model}

The variation in strain rate shown in Figure 1 results in two sources of error when estimating the true stress from the force displacement data of the tensile tests. First, the force measured during the test corresponds to the actual strain rate rather than the target value. Because Figure 1 shows that the strain rate is initially below the target value, the load (and stress) at the target strain rate would be higher than that measured. Second, as the test progresses, the actual strain in the center of the specimen lags behind the expected strain. This results in a larger crosssectional area than would be expected assuming a constant, known strain rate throughout the test. The magnitude of these errors in the predicted stress can be estimated using the strain rate history in Figure 1.

The strain rate sensitivity exponent, $\mathrm{m}$, can be used to approximate the error in the predicted stress from the error in the strain rate. The strain rate correction factor on stress, $f_{1}$, is equal to the ratio of the stress at the target strain rate, $\sigma_{\mathrm{T}}$, divided by the stress at the actual strain, $\sigma_{\mathrm{A}}$ :

$$
f_{1}=\frac{\sigma_{T}}{\sigma_{A}}=\left(\frac{\dot{\varepsilon}_{T}}{\dot{\varepsilon}_{A}}\right)^{m}
$$

Iwasaki et al. (3) provides curves of $m$ versus strain and strain rate for the alloy used in this study (Al-5083 produced by Sky Aluminum Company). Although $\mathrm{m}$ varies with both strain and strain rate, only the variation of $\mathrm{m}$ with strain was considered here since our forming experiments were performed at strain rates corresponding to near the peak $\mathrm{m}$ value (where $\mathrm{m}$ is relatively constant with strain rate). Figure 2 shows the relationship of $m$ value versus strain used in these calculations.

If a constant strain rate is applied during a test, then the target cross-sectional area, $\mathrm{A}_{\mathrm{T}}$, of the specimen can be easily estimated through time as:

$$
A_{T}=\frac{A_{0}}{e^{\dot{\varepsilon}_{T} t}}=\frac{A_{0}}{e^{\varepsilon_{T}}}
$$


Where $A_{0}$ is the initial cross-sectional area, $\dot{\varepsilon}_{\mathrm{T}}$ is the target strain rate, $t$ is time, and $\varepsilon_{\mathrm{T}}$ is true strain. However, if the actual strain rate varies with time as in Figure 1, then the actual area, $A_{A}$, must be calculated by first integrating the strain rate history to calculate the true strain.

$$
\varepsilon_{A}=\int_{0}^{t} \dot{\varepsilon}(t) d t
$$

The actual area can then be estimated as:

$$
A_{A}=\frac{A_{0}}{e^{\varepsilon_{A}}}
$$

The area stress correction is equal to the ratio of the area corresponding to the constant, target strain rate divided by the actual area.

$$
f_{2}=\frac{A_{T}}{A_{A}}=\frac{e^{\varepsilon_{A}}}{e^{\varepsilon_{T}}}=e^{\left(\varepsilon_{A}-\varepsilon_{T}\right)}
$$

Figure 3 shows the strain rate and area correction factors on stress for the strain rate history of Figure 1. Also shown is the combined stress correction factor; the product of the strain rate and area factors. These calculations suggest that the actual stress may be $30 \%$ higher at zero strain than would have been predicted from the tensile tests because of the error in strain rate. Later in the test (0.6 true strain), the accumulated error in the cross-sectional area results in the actual stress being about $10 \%$ lower than the value that would be calculated from the tensile test data.

The results shown in Figures 1 and 3 are actually the result of an iterative process where the initial combined stress correction factor was applied to the constitutive relation and the tensile test model was rerun to estimate a new strain rate variation throughout the test. Convergence on the strain rate variation of Figure 1 was achieved in three iterations. Figure 3 shows the corresponding stress correction factors. The final correction factors were applied to the constitutive relation and Figure 4 shows both the uncorrected and corrected stress versus strain from the constitutive relation at several strain rates.

\section{$\underline{\text { Stress Correction for a Longer Specimen }}$}

Since discovering the shortcomings in our testing procedures, researchers at PNL have begun using longer tension specimens with a gauge length-to-width ratio of $4: 1$. The gauge section of PNL's specimens now measures $25.4-\mathrm{mm}$ (1-in.) long, 6.35-mm (0.25-in.) wide, and 2-mm $(0.078$-in.) thick. Finite element models of the longer specimen were constructed and the aboveerror estimation procedure was repeated. Figure 5 shows that the strain rate of the longer specimen may initially be $75 \%$ of the target value rather than $65 \%$ as previously estimated for the specimen with a 2:1 length-to-width ratio. Figure 6 estimates that the $4: 1$ specimen still contains about $18 \%$ error in the stress at zero strain due to the error in strain rate. Therefore, lengthening the specimen reduces the error in strain rate (and stress), but it does not eliminate it. 
A possible solution to further reduce testing errors is to adjust the displacement history to enforce a constant strain rate during the test and, thus, counteract the effect of material flow from the specimen grips. The finite element models of the 2:1 and 4:1 specimens were rerun with a solution control routine that adjusted the displacement rate to maintain the target strain rate at the center of the specimen gauge length. Figure 7 shows these displacement histories as a fraction of the exponential displacement history given by Equation (2). This suggests that to maintain a constant strain rate of $0.001 /$ second, the exponential displacement history should be initially increased by a factor of 1.7 if the $2: 1$ specimen is used or by a factor of 1.4 if the $4: 1$ specimen is used.

\section{Comparison of Tray Forming Experiments and Model Results}

A long rectangular tray was chosen for the comparisons of forming experiments with the finite element model results. The long tray provides a plane strain section in the center of the long side, plus areas of biaxial straining as the sheet forms into the corners. PNL's forming tests show that the strains at he strain. The die cavity used to form the trays measures $5.1-\mathrm{cm}(2-\mathrm{in}$.) wide, $20.3-\mathrm{cm}(8-\mathrm{in}$.) long, and $2.5-\mathrm{cm}$ (1-in.) deep. The clamped area of the flat sheet measures $12.7-\mathrm{cm}(5-\mathrm{in}$.) by $27.9-$ $\mathrm{cm}$ (11-in.), leaving a 3.8-cm (1.5-in.) rim surrounding the cavity. A die entrance radius of 3.2$\mathrm{mm}(0.125$-in.) makes the transition from the flat rim to the rectangular cavity. Figure 8 shows the one-quarter symmetry model of the sheet and die as constructed using the MARC finite element code (4). The model makes use of three-dimensional membrane elements and the rigid plastic flow formulation. The sheet thickness was $2-\mathrm{mm}(0.078-\mathrm{in}$.) and a coefficient of friction equal to 0.2 best reproduced the thinning measured in the forming tests.

\section{Prediction of Forming Pressure History}

One of the primary objectives of simulating the SPF process is to predict an optimized forming cycle. A common strategy for estimating an optimized pressure history is to adjust the pressure load applied in the finite element model to maintain optimum superplastic flow throughout the forming cycle. Optimum flow conditions are defined here as maintaining the maximum strain rate in the component at the upper end of the superplastic range. The objective is to form the part in as little time as possible and yet avoid localized thinning (necking) and cavifition. PNL's approach has been to find the element with the maximum equivalent plastic strain rate at each timestep and adjust the pressure load of the next timestep to maintain the maximum strain rate at a target value throughout the forming simulation. Choice of the target strain rate has been based on maintaining the maximum strain rate in the model at the upper end of the superplastic range. In the current study, the target strain rate was $0.001 /$ second.

PNL's experience has shown that the absolute maximum strain rate predicted by the model (at a given timestep) may be very localized (i.e., centered about a single node) and the result of several combined factors such as local mesh refinement, timestep size, and local contact conditions (i.e., whether or not contact has just occurred or if stick or slip friction conditions exist). An oscillating pressure history can result if pressure is calculated using such a local anomaly. Therefore, an averaging method was adopted for the current study that considered a subset of elements with the highest strain rates. This procedure helped to smooth some of the non-physical behavior observed in the numerical models. Figure 9 shows the pressure history 
developed using the finite element model. Superimposed on Figure 9 is the bulge height of the sheet (both model and test results) as it forms into the die.

\section{Comparison of Results}

Forming tests were run for elapsed times of 3,6, and 9 minutes for comparison with the model results. The finite element models were run with and without the stress correction (corresponding to the short 2:1 specimen) applied to the constitutive model. Figure 9 compares the bulge height versus time for the models and experiments. This shows that including the stress correction increases the time for the bulge to touch the bottom of the die cavity from 5 to 6 minutes. Thus, it is predicted that the inaccurate test procedures could introduce about $17 \%$ error in the forming time. This trend was also consistent for longer times as the sheet formed into the corners of the die. Although including the stress correction in the model shifts the model predictions toward the experimental results, the both models predict significantly more rapid forming than the forming experiments showed. As stated previously, this is because of the constitutive model being fit to a compilation of data from several sources rather than data for this specific manufacturer and heat of material.

\section{$\underline{\text { Summary and Conclusions }}$}

This paper estimates the level of error in a constitutive model that was based on tensile test data from short specimens (gauge length-to-width ratio of 2:1). Finite element models that applied the exponential "constant strain rate" test predict that the strain rate actually begins considerably below the target value and increases to surpass the target strain rate later in the test. This trend was confirmed experimentally with interrupted tensile tests. The error in strain rate translates to an error in the true stress versus strain relations that were developed from the test data. The magnitude of this error was estimated using the variation in strain rate predicted by the finite

element model. For the short 2:1 specimen, the stress at the target strain rate was estimated to initially be $30 \%$ higher than that predicted from the tensile tests. Stress correction factors were also estimated for a longer $4: 1$ specimen. This predicted that the stress estimated from the tests should be initially increased by $18 \%$ rather than the $30 \%$ factor of the $2: 1$ specimen. Therefore, increasing specimen length alone reduces the error, but does not eliminate it.

To further reduce testing errors, it is necessary to adjust the displacement history such as to counteract the effect of material flow from the specimen grips. The finite element models were rerun with a control routine that enforced a constant strain rate of $0.001 / \mathrm{second}$ in the center of the gauge length. This work predicted that the often-used exponential displacement history must be increased by an initial factor of 1.7 for the $2: 1$ specimen and 1.4 for the $4: 1$ specimen. The relationship of this adjustment factor with strain is presented for both the 2:1 and 4:1 specimens.

Finite element models were also constructed of a long; rectangular tray to estimate the effect of the constitutive model error on predicted forming results. This work estimated that the inaccuracies in typical SPF testing procedures could introduce about a $17 \%$ error in the forming time estimated by the finite element models.

\section{$\underline{\text { References }}$}

1. K. I. Johnson et al., "The Effect of Specimen Geometry on the Accuracy of Constitutive Relations in a Superplastic 5083 Aluminum Alloy." In the proceedings of the 1994 
International Conference on Superplasticity in Advanced Materials, (ICSAM-94), May 24-26, 1994. Moscow, Russia.

2. C. H. Hamilton et al. in Superplasticity in Advanced Materials, ICSAM'91, S. Hori, M. Tokizane, and N. Furushiro eds., Osaka, Japan, (1991), 127-132.

3. I. Iwasaki et al. in Superplasticity in Advanced Materials, ICSAM'91, S. Hori, M. Tokizane, and N. Furushiro eds, Osaka, Japan, (1991), 447-452.

4. MARC Analysis Research Corporation, The MARC Finite Element Program. Revision K.6.1. (MARC Analysis Research Corporation, Palo Alto, California, 1994). 


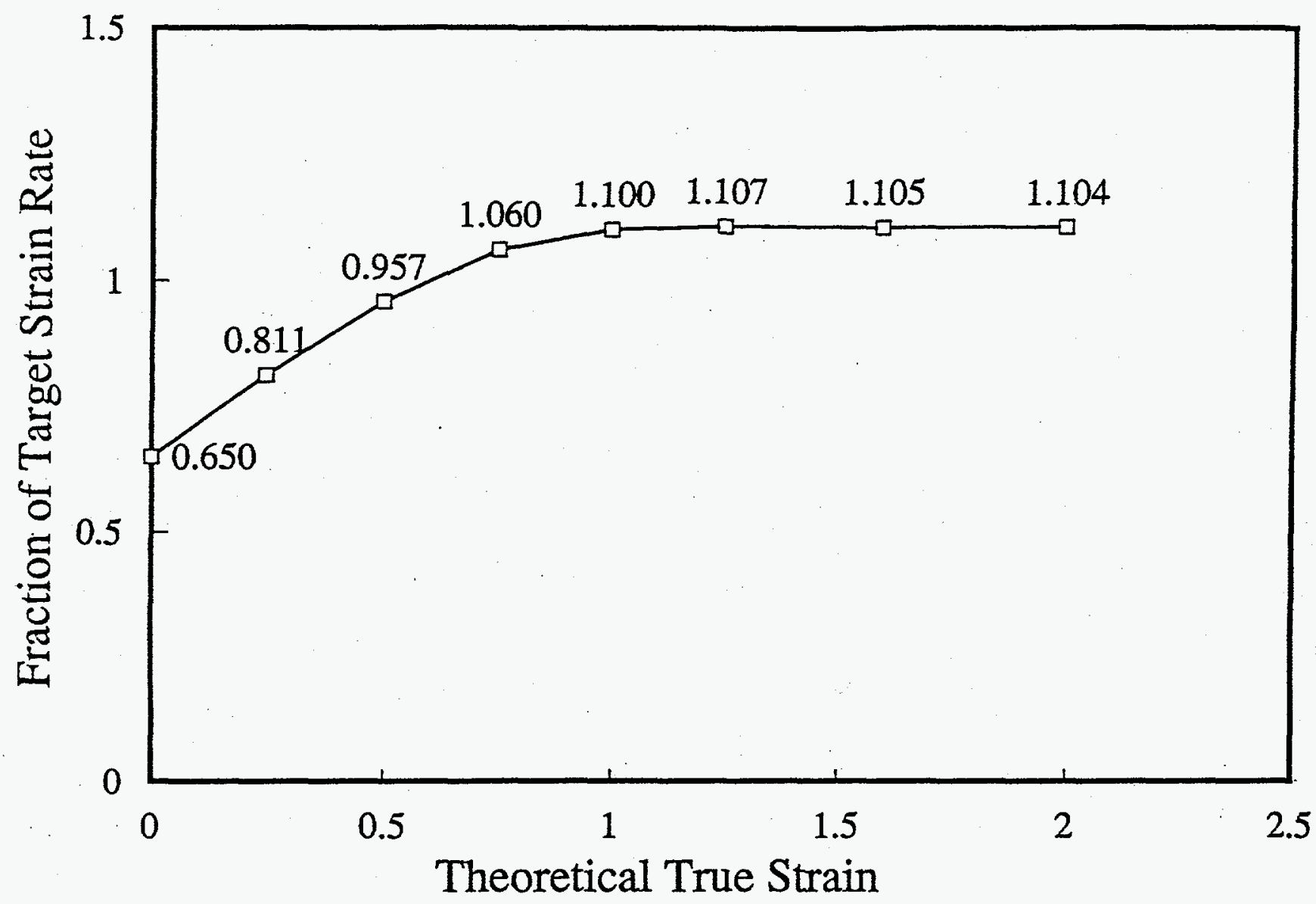

Figure 1. Actual strain rate achieved with a short tension specimen (gauge length-towidth ratio of 2:1) and an exponential displacement history. 


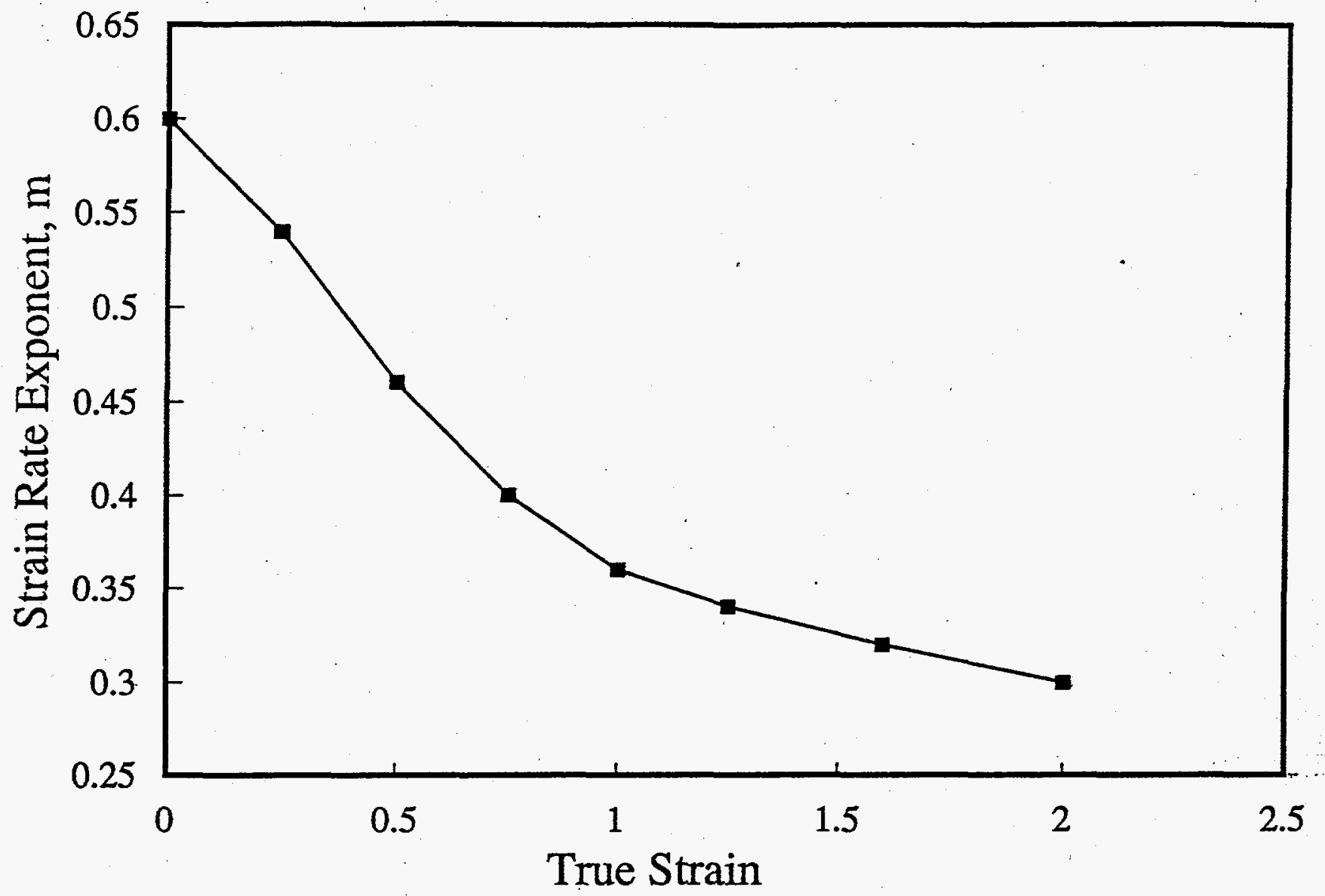

Figure 2. Strain rate sensitivity exponent, $\mathrm{m}$, versus strain used in estimating stress error [from Iwasaki et. al (2)]. 


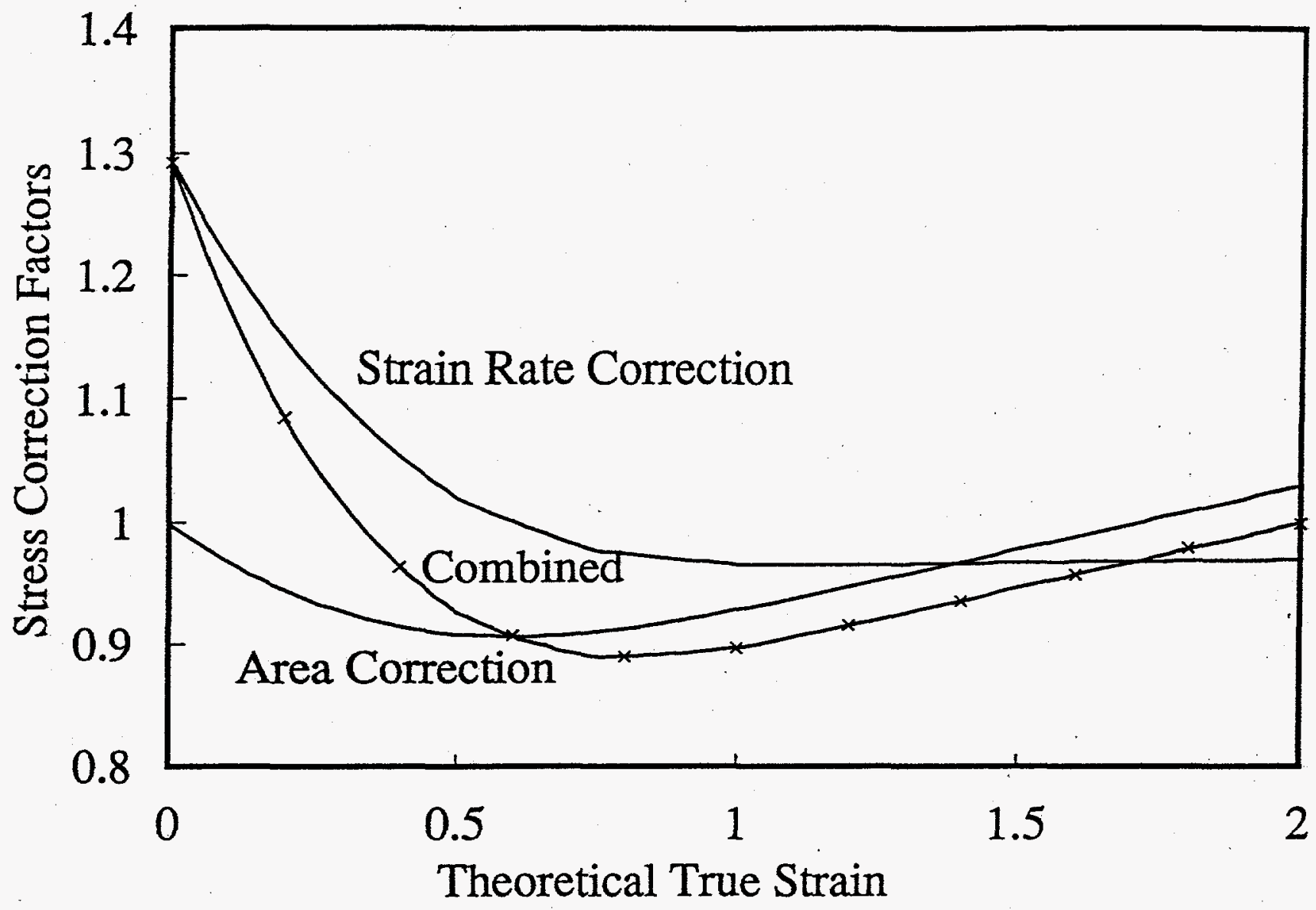

Figure 3. Stress correction factors estimated for the short 2:1 specimen. 


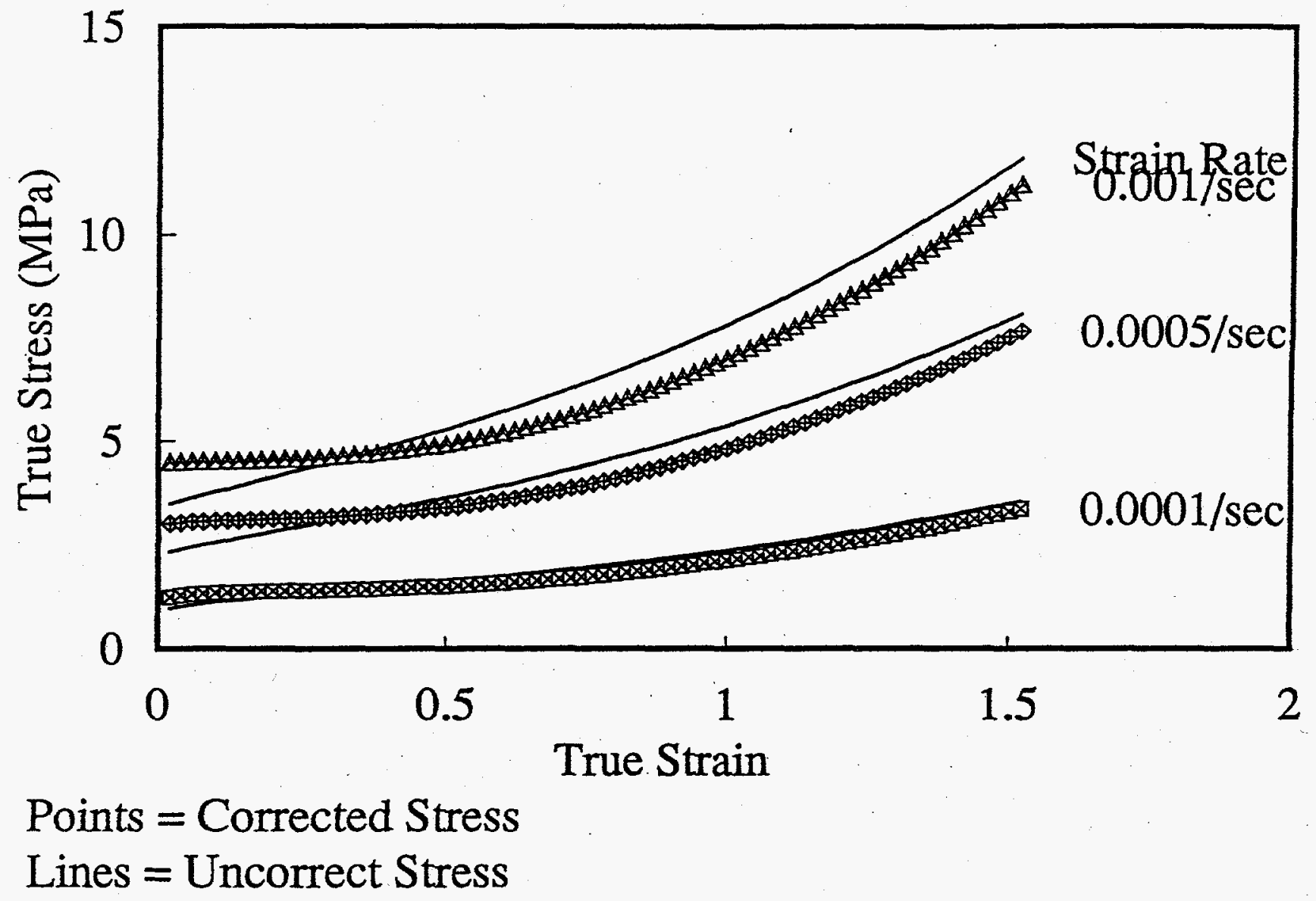

Figure 4. Comparison of corrected and uncorrected stress versus strain for three strain rates. 


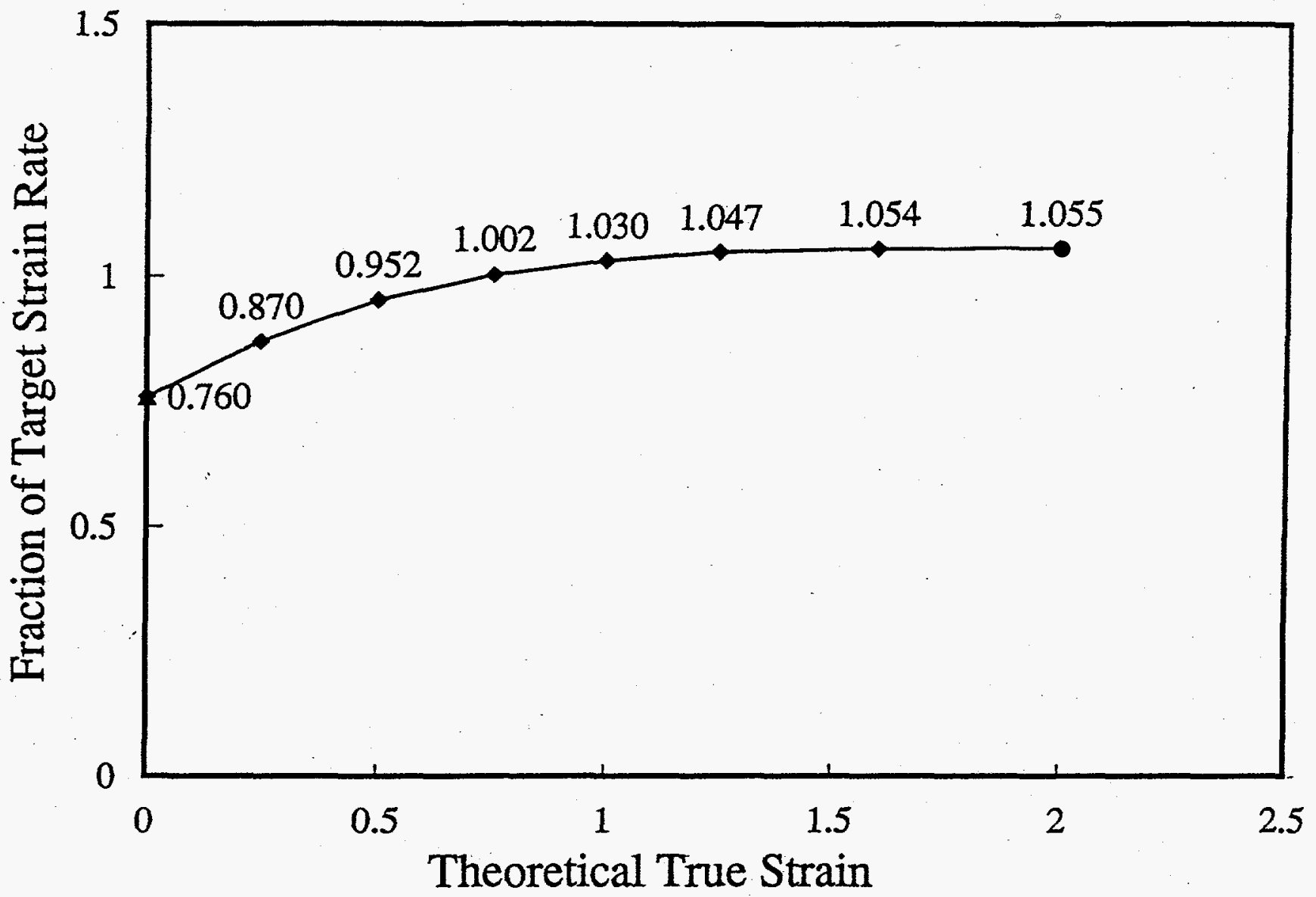

Figure 5. Actual strain rate achieved with a longer tension specimen (gauge length-towidth ratio of $4: 1$ ) and an exponential displacement history. 


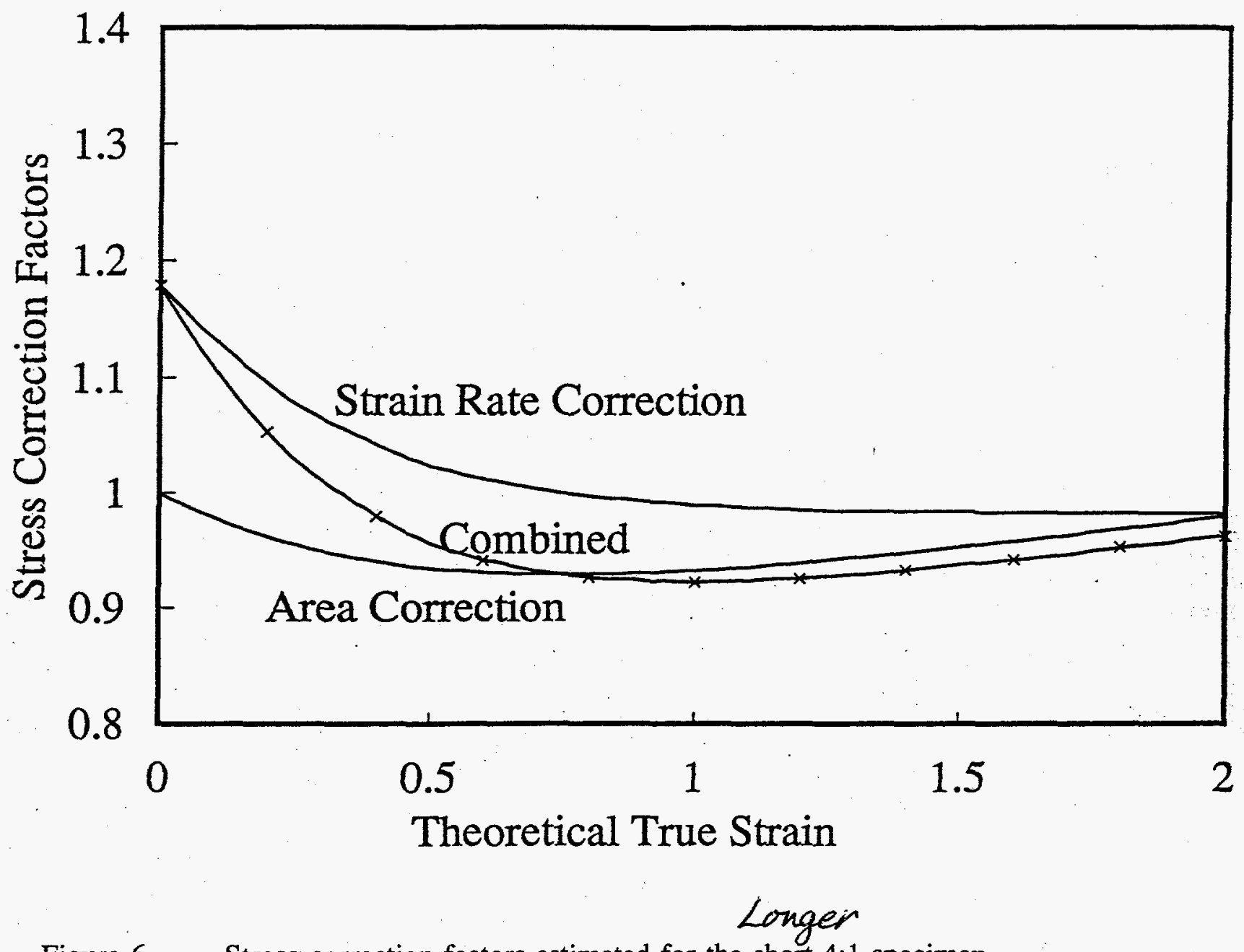

Figure 6. Stress correction factors estimated for the $4: 1$ specimen. 


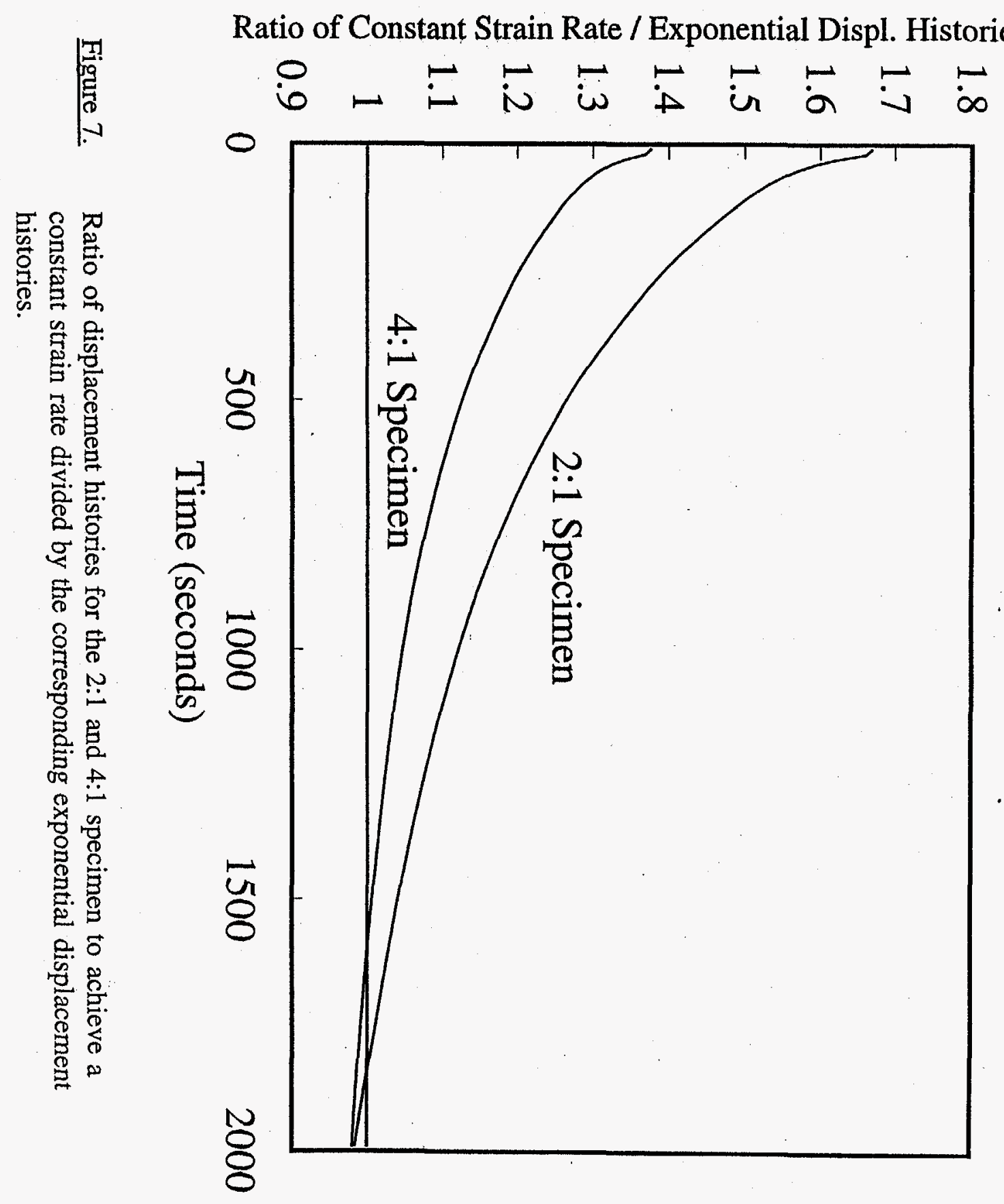




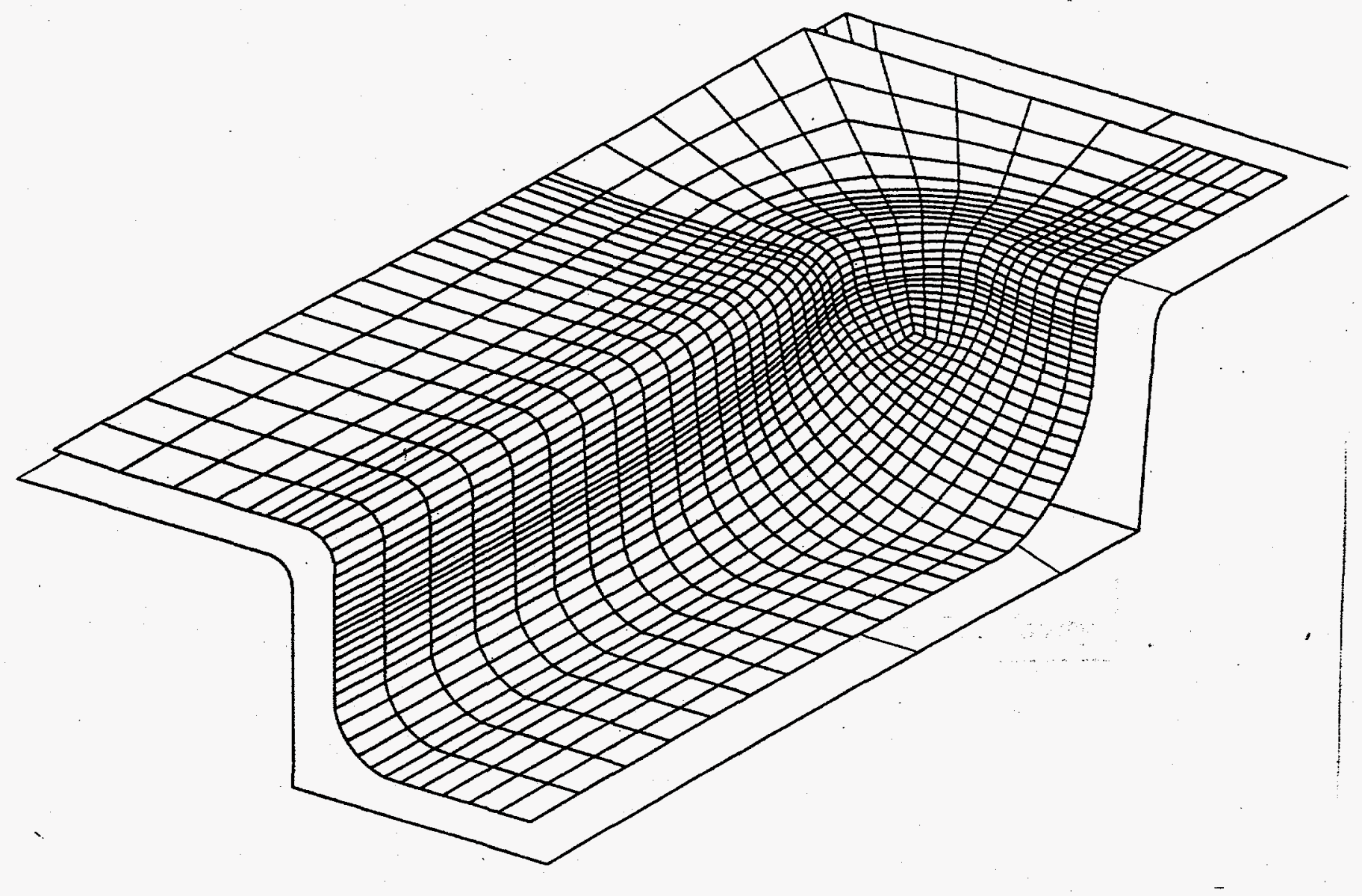

Figure 8. The finite element model used to simulate the rectangular tray. 


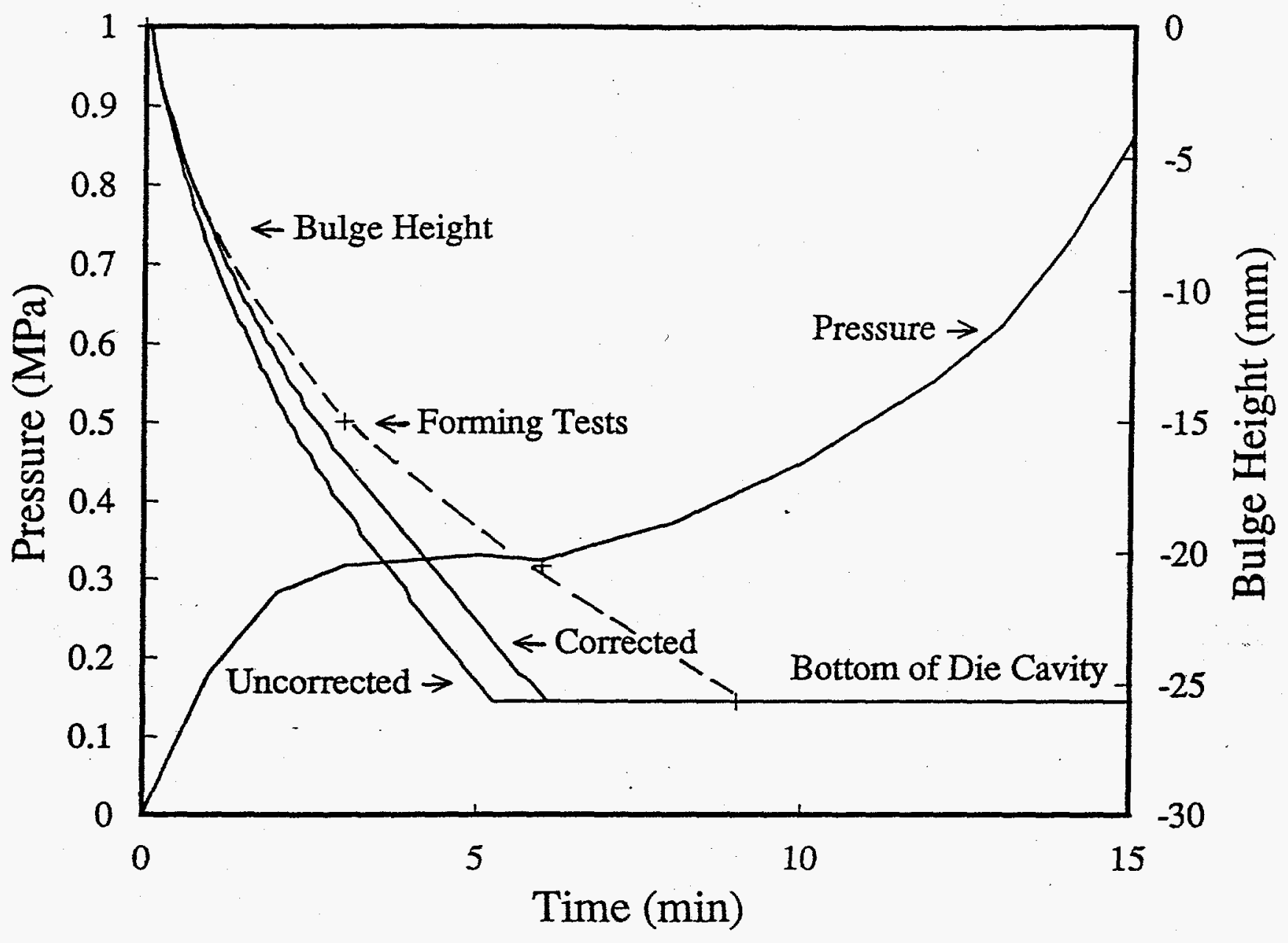

Figure 9. Pressure history applied to the tray model and bugle height versus time from the models and forming tests. 